\title{
BNCC e formação de professores: concepções, tensões, atores e estratégias
}

\author{
MÁRCIA ANGELA DA S. AGUIAR* \\ Universidade Federal de Pernambuco, Recife- PE. Brasil. \\ LUIZ FERNANDES DOURADO** \\ Universidade Federal de Goiás, Goiânia- GO. Brasil.
}

$\mathrm{N}$

o Brasil, a sociedade civil organizada, em especial, as associações científicas e as entidades sindicais de educação, desde a década de 1980, teve efetiva participação na definição de marcos legais que orientam a organização da educação brasileira, mediante a promoção das conferências nacionais de educação (CBE, Coned, Conebe 2008, Conae 2010 e Conae 2014). Desse modo, contribuiu para o capítulo de Educação na Constituição Federal de 1988, na formulação da Lei de Diretrizes e Bases da Educação Nacional (LDB 1996) e na definição do Plano Nacional de Educação 20142024 (Lei n⿳0 13.005/2014) ${ }^{1}$, dentre outras legislações pertinentes.

Como é comum acontecer nas democracias, as concepções e as políticas educacionais são objeto de disputa entre grupos com interesses diversos e com recursos de poder que influenciam as escolhas e o desenvolvimento de ações na máquina governamental. Isto pode ser visto, com clareza, no Ministério da Educação, na Secretaria de Educação Básica, na primeira gestão da presidenta Dilma Rousseff, no tocante à opção, como prioridade das políticas educacionais, por uma das estratégias das Meta 2 e 3, inscrita no Plano Nacional de Educação 2014-2018, atinente à instituição de uma Base Nacional Comum Curricular (BNCC).

Essa prioridade política assumida pelo MEC, influenciada principalmente pelo Conselho Nacional de Educação (CNE) e instituições e fundações privadas, como o Movimento Todos pela Educação, Fundação Lemann, Movimento pela Base, Unibanco, dentre outros, deixou em segundo plano importantes metas estabelecidas no PNE e que

* É doutora em Educação pela Universidade de São Paulo. Professora titular, atuando na graduação de Pedagogia e no Programa de Pós-Graduação em Educação do Centro de Educação da Universidade Federal de Pernambuco. Ex-membro da Câmara de Educação Superior do Conselho Nacional de Educação (CES/ CNE). E-mail: <marciaangelaaguiar@gmail.com>.

* É É doutor em Educação pela Universidade Federal do Rio de Janeiro. Professor titular e emérito da Universidade Federal de Goiás, Ex-membro da Câmara de Educação Superior do Conselho Nacional de Educação (CES/CNE). E-mail: <luizdourado2@gmail.com>. 
deveriam ter urgência em sua materialização nas três esferas de governo, dentre as quais destacam-se as que garantem a universalização da educação básica até 2016 (metas 1, 2 e 3).

De fato, quando o ministro da Educação Cid Gomes, em 2015, torna-se titular do MEC, efetivou o passo inicial para inscrever como prioridade na agenda nacional da educação a definição de uma base nacional comum curricular, sob o argumento de cumprir o PNE e outras legislações educacionais, a despeito da oposição pelas principais associações científicas da área, como a Associação Nacional de Pós-Graduação e Pesquisa em Educação (ANPEd), Associação Nacional de Política e Administração da Educação (Anpae), Associação Nacional pela Formação dos Profissionais da Educação (Anfope) e Associação Brasileira de Currículo $(\mathrm{ABdC})$, que se contrapunham à padronização e homogeneização de um currículo nacional para a educação básica.

Essa ação ministerial direcionada à educação básica permaneceu como prioridade na gestão dos demais titulares do MEC (Ministros Renato Janine Ribeiro e Aloizio Mercadante), contando com a participação, em seu processo de formulação, de comissões constituídas por profissionais e especialistas de universidades e do campo educacional. Todavia, esse processo seguiu outro rumo com a interrupção do governo da presidenta Dilma Rousseff, após o impeachment, em agosto de 2016.

Sob o governo do presidente Michel Temer, as políticas educacionais em curso são interrompidas e/ou tomam nova configuração, como vai ocorrer com o Fórum Nacional de Educação (FNE), cujas atribuições foram alteradas e substituída a sua coordenação, e com a Conferência Nacional de Educação (Conae) prevista para ser realizada em 2018, que teve modificada sua composição, o que motivou a saída das associações científicas de educação que instituiram o Fórum Nacional Popular de Educação (FNPE) e a Conferência Nacional Popular de Educação (Conape). Mudanças também fez o novo governo no processo de construção da Base Nacional Comum Curricular (BNCC).

Com efeito, sob o comando do MEC pelo titular José Mendonça Filho, a BNCC vai ser redirecionada, com a ruptura da concepção de educação básica, que tinha sido uma conquista da sociedade brasileira. Rompe-se, assim, com a organicidade da educação básica, e o MEC constituiu um Comitê Gestor, coordenado pela Secretaria Executiva, que vai apresentar ao Conselho Nacional de Educação (CNE) a $3^{\underline{a}}$ versão da BNCC relativa à educação infantil e ensino médio, consagrando, então, a divisão ${ }^{2}$.

Na sequência, o Comitê Gestor acatou ato do Governo Federal, que emitiu uma medida provisória para efetivar a reforma do ensino médio, desconsiderando não só as ações em curso do governo anterior, como também os projetos em discussão no Congresso Nacional. Assim, encaminhou ao CNE a BNCC do ensino médio, reafirmando a divisão da educação básica.

Como foi visto, aos poucos, o processo de elaboração da BNCC, conduzido de forma ininterrupta nas gestões de quatro ministros de educação, com ritos, concepções e dinâmicas variadas, passou a ser o carro-chefe das políticas desenvolvidas pelo MEC, uma vez 
que, para este órgão, a base poderia se tornar o ponto nodal para uma ampla reforma da educação básica, o que abrangia a formalização e a articulação entre currículos escolares, a formação de professores, a gestão da educação e os processos avaliativos.

Nesse contexto, a formação dos professores sobressai, por ser um elemento estratégico para materializar a pretendida reforma da educação básica, atendendo aos reclamos do mercado, que pugna pela formação do sujeito produtivo e disciplinado.

O presente dossiê, a partir de várias reflexões e estudos de pesquisadores e pesquisadoras aqui apresentados, problematiza a instituição de uma base nacional comum curricular segmentada, bem como o processo açodado de sua tramitação e a proposição de base para a formação de professores e professoras, no governo de Michel Temer, como elementos fundamentais da política pública de educação em curso nos anos 2016 e 2017, e que adotou como eixos, segundo as análises, a padronização curricular, a submissão aos padrões da OCDE, a orientação de segmentos do setor privado.

Este dossiê busca trazer à luz os bastidores deste cenário mediante o exame das concepções que embasaram a proposta da BNCC, das ideias e proposições das principais instâncias e instituições que a influenciaram e das medidas concretas para sua materialização pelos diversos atores, sublinhando as estratégias que buscam sua institucionalização nos sistemas educativos e nas instituições educativas de educação básica. De forma similar, examina a política nacional de formação dos profissionais da educação básica aprovada pelo Decreto 8752/2016, em consonância com o PNE, e a proposta de política nacional de professores, formulada pelo MEC, buscando identificar aproximações e paradoxos. Busca, ainda, recuperar o movimento vigoroso das entidades do campo na discussão e proposição sobre a BNCC e a política de formação de professores.

Os artigos que compõem este Dossiê estão agrupados em torno de dois eixos, que se articulam, a saber: I) Base Nacional Comum Curricular: concepções e desdobramentos político-pedagógicos na educação básica; II) Base Nacional Comum Curricular e Política de Formação dos Professores: limites e interfaces.

Apresenta-se, assim, artigos vinculados ao eixo I Base Nacional Comum Curricular: concepções e desdobramentos político-pedagógicos na educação básica, como o de Elizabeth Macedo, que parte da "noção pós-fundacional de política» e focaliza nas competências e no germe da comparação a maneira como "a noção de competência geral, que passou a estruturar a Base pós-impeachment, vem sendo significada" nos dias atuais. A autora entende que "há um alinhamento da política educacional do País à governança da OCDE baseada na comparabilidade" e conclui o texto propondo o "uso de outras referências para a construção de uma base de valorização profissional e condições de infraestrutura para uma educação de qualidade".

Já Alice Cassimiro Lopes, problematiza "as relações entre disciplinas escolares e propostas de integração nas políticas de currículo, com foco na proposta de itinerários formativos e de organização por competências da Base Nacional Comum Curricular para 
o ensino médio" e destaca "alguns efeitos que produzem nas identificações docentes, bem como as tentativas de controle dos projetos de vida dos estudantes". A autora conclui o texto apontando que "a proposta de integração curricular apresentada pela BNCC do ensino médio não viabiliza a flexibilidade curricular a qual alude" . E vai além, ao afirmar que tal proposta, "tende a ser restritiva de possibilidades de integração curricular por permanecer tentando controlar o projeto de futuro dos jovens estudantes por meio de metas fixadas a priori".

Ivone Garcia Barbosa, Telma Aparecida Teles Martins Silveira e Marcos Antonio Soares focalizam os princípios orientadores da BNCC, a partir de análise dialética materialista como referência e sua articulação "com uma concepção pragmática de educação vinculada ao modelo neoliberal". Neste artigo são enfatizadas as contradições e implicações da BNCC para a educação infantil a partir de concepção pragmática.

Maria Luiza Süssekind, por sua vez, parte "da percepção de que o modo de conhecer moderno engendra também suas ignorâncias e aponta, em diálogo com as teorias de Boaventura Santos, que a reforma é arrogante, indolente e malévola, produz injustiças, invisibilidades e inexistências". Conclui afirmando que o conhecimento curricular democrático é deslocamento, conversa, e resistência ao pensamento único.

Por fim, Emina Santos e Vivian de Lima Cabral sinalizam análises sobre a importância das diretrizes, como referência para a elaboração de propostas pedagógicas para as redes de ensino e suas instituições, em contraposição a BNCC, visando a melhoria da qualidade da educação básica a partir do conceito de formação humanista.

Compondo o item II Base Nacional Comum Curricular e Política de Formação dos Professores, limites e interfaces, ressaltamos as análises feitas por Monica Ribeiro da Silva, que põe em questão "o referencial com base em competências na definição dos currículos da formação de professores", mediante análise da "sua origem no campo do trabalho em geral" e de uma discussão sobre "a relação entre BNCC, formação de professores e o modelo de competências, considerando a experiência brasileira e sua retomada nos documentos atuais de políticas curriculares". A autora conclui "pela impertinência desse referencial, considerando, sobretudo, seu caráter economicista e reducionista".

Em seu artigo, Ângela Cristina Alves Albino e Andréia Ferreira da Silva examinam a proposta de formação inserida na BNCC, bem como a versão preliminar da Base Nacional Comum para a Formação de Professores, de dezembro de 2018, considerando o contexto de disputas em torno de um "projeto curricular para a educação no país". Já Isabel Maria Sabino de Farias problematiza e analisa a "proposta para Base Nacional Comum da Formação de Professores da Educação Básica" apresentada ao Conselho Nacional de Educação pelo Ministério da educação, em dezembro de 2018, na gestão do presidente Michel Temer. Sua análise se contrapõe à concepção de que "professores bem preparados fazem a diferença no desempenho discente e a universidade não sabe formar professores conforma o consenso discursivo subliminar sob o qual se ergue a visão 
sistêmica da formação de professores neste documento, que assume o desenvolvimento de competências como referencial básico".

Roselane Fátima Campos, Zenilde Durli e Rosânia Campos, abordam o lugar estratégico da formação de professores nos processos de mudanças na educação, analisando, entre 2009 e 2017, as orientações governamentais que articulam currículo e formação. Destacam a ação de redes empresariais com influência no governo e "as estratégias empresariais de formação continuada dirigidas, em particular, para profissionais da educação infantil".

Álvaro Moreira Hypolito discute a formação docente, considerando algumas relações entre políticas globais e políticas curriculares nacionais, bem como entre a Base Nacional Comum Curricular e as políticas nacionais mais amplas.

Ao fim, Nathália Fernandes Egito Rocha e Maria Zuleide da Costa Pereira, a partir da pesquisa de doutorado da primeira, entendem que "a política da BNCC constrói um discurso normatizador e regulador, principalmente quanto à sua intencionalidade de alinhamento das políticas de avaliação, formação docente, material didático e outras à política curricular". Ressaltam, no entanto, que, a despeito de a BNCC poder "introduzir mudanças e efeitos na dimensão da prática e da organização da escola, ela não pode controlar a dinâmica e a singularidade do contexto da micropolítica".

Nossa expectativa é de que estas análises contribuam para a discussão sobre as concepções e desdobramentos político-pedagógicos da BNCC na educação básica e para a apreensão dos seus limites e interfaces com a política de formação dos professores, sobretudo no contexto atual brasileiro, demarcado pelo neoliberalismo e por uma visão conservadora de mundo, sociedade e educação, em que as políticas e gestão para a educação básica caminham para um retrocesso sem precedentes. Este cenário, que se expressa por políticas de ajuste fiscal, pela centralidade conferida ao "movimento escola sem partido" e pela secundarização do Plano Nacional de Educação 2014-2024, requer discussões e lutas em prol da defesa dos marcos constitucionais, visando garantir o Estado Democrático de Direito e a defesa histórica da educação básica, pública, laica, gratuita, democrática e de qualidade social para todos e todas.

\section{Notas}

1 DOURADO, L.F. Plano Nacional de Educação: o epicentro das políticas de Estado para a educação brasileira. Goiânia: Imprensa Universitária/ ANPAE, 2017. 216p.

2 AGUIAR, M.A.S.; DOURADO, L.F. (Orgs.). A BNCC na contramão do PNE 2014-2024: avaliação e perspectivas. [Livro Eletrônico]. - Recife: ANPAE, 2018. 